\title{
Embryo-lethal phenotypes in early abp1 mutants are due to disruption of the neighboring BSM gene [version 1; peer
} review: 3 approved] Jaroslav Michalko1,2, Marta Dravecká1, Tobias Bollenbach¹, Jiří Friml1

${ }^{1}$ Institute of Science and Technology Austria (IST Austria), Klosterneuburg, 3400, Austria

${ }^{2}$ Institute of Plant Genetics and Biotechnology, Slovak Academy of Sciences, Nitra, 95007, Slovakia

V1 First published: 23 Oct 2015, 4:1104

https://doi.org/10.12688/f1000research.7143.1

Latest published: 23 Oct 2015, 4:1104

https://doi.org/10.12688/f1000research.7143.1

\section{Abstract}

The Auxin Binding Protein1 (ABP1) has been identified based on its ability to bind auxin with high affinity and studied for a long time as a prime candidate for the extracellular auxin receptor responsible for mediating in particular the fast non-transcriptional auxin responses. However, the contradiction between the embryo-lethal phenotypes of the originally described Arabidopsis T-DNA insertional knock-out alleles (abp1-1 and abp1-1s) and the wild type-like phenotypes of other recently described loss-of-function alleles (abp1-c1 and abp1-TD1) questions the biological importance of ABP1 and relevance of the previous genetic studies. Here we show that there is no hidden copy of the $A B P 1$ gene in the Arabidopsis genome but the embryo-lethal phenotypes of $a b p 1-1$ and abp1-1s alleles are very similar to the knockout phenotypes of the neighboring gene, BELAYA SMERT (BSM).

Furthermore, the allelic complementation test between $b s m$ and $a b p 1$ alleles shows that the embryo-lethality in the abp1-1 and abp1-1s alleles is caused by the off-target disruption of the BSM locus by the TDNA insertions. This clarifies the controversy of different phenotypes among published abp1 knock-out alleles and asks for reflections on the developmental role of ABP1.

\section{Keywords}

Auxin-binding protein 1, ABP1, BELAYA SMERT, , BSM, embryolethality, allelism, short read DNA mapping

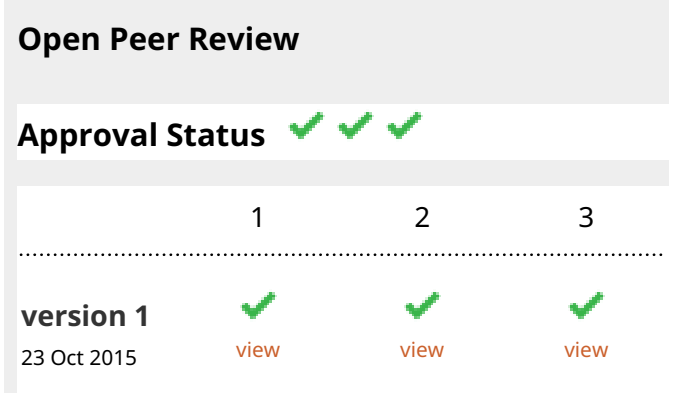

1. Lars Ostergaard, John Innes Centre, Norwich, UK

2. Richard M. Napier, University of Warwick, Coventry, UK

3. Christian Luschnig, University of Natural

Resources and Life Sciences, Vienna, Austria Any reports and responses or comments on the article can be found at the end of the article. 
Corresponding author: Jiř́ Friml (jiri.friml@ist.ac.at)

Competing interests: No competing interests were disclosed.

Grant information: This work was supported by ERC Independent Research grant (ERC-2011-StG-20101109-PSDP to JF). JM internship was supported by the grant "Action Austria - Slovakia".

Copyright: @ 2015 Michalko J et al. This is an open access article distributed under the terms of the Creative Commons Attribution License, which permits unrestricted use, distribution, and reproduction in any medium, provided the original work is properly cited. Data associated with the article are available under the terms of the Creative Commons Zero "No rights reserved" data waiver (CC0 1.0 Public domain dedication).

How to cite this article: Michalko J, Dravecká M, Bollenbach T and Friml J. Embryo-lethal phenotypes in early abp1 mutants are due to disruption of the neighboring BSM gene [version 1; peer review: 3 approved] F1000Research 2015, 4:1104 https://doi.org/10.12688/f1000research.7143.1

First published: 23 Oct 2015, 4:1104 https://doi.org/10.12688/f1000research.7143.1 


\section{Introduction}

The plant hormone auxin plays a central role in plant growth and development. Sensing and interpreting the fluctuating cellular auxin levels is crucial for mediating the corresponding physiological and developmental responses (Enders \& Strader, 2015; Grunewald \& Friml, 2010). Currently, two main auxin receptor/co-receptor systems are known and have been proposed to activate a range of cellular responses; among them the Auxin Binding Protein 1 (ABP1) has been considered as a prime candidate for the extracellular auxin receptor (Grones \& Friml, 2015).

The first notion of ABP1 was based on the auxin-binding activity at the plant cell surface and in the endoplasmic reticulum in crude membrane preparations of etiolated coleoptiles (Hertel et al., 1972). This binding activity was characterized over the next decade by detailed biochemical studies (Batt et al., 1976; Ray et al., 1977). ABP1 was firstly purified from maize coleoptile cells (Lobler \& Klambt, 1985) as a soluble 22-kDa large glycoprotein and later its crystal structure was elucidated (Woo et al., 2002).

The biological function and importance of ABP1 has been investigated extensively. Early studies have demonstrated that APB1 is involved in the rapid regulation of the membrane potential and ion fluxes at the plasma membrane and that it mediates the auxininduced cell swelling, cell elongation, and cell division (Braun et al., 2008; Steffens et al., 2001; Tromas et al., 2009; Yamagami et al., 2004). In the presence of auxin, ABP1 activates the $\mathrm{H}^{+}$pump ATPase that acidifies the extracellular space, presumably triggering cell wall loosening (Cosgrove, 2000).

With the advent of the genomic era and Arabidopsis thaliana as a model system, genetic tools have been adopted to facilitate the studies of the ABP1 developmental roles. Using a reverse genetic approach, two independent Arabidopsis thaliana knock-out alleles of ABPl gene were identified, abpl-1 and abpl-1s (Chen et al., 2001; Tzafrir et al., 2004) and both were reported to be allelic and embryo-lethal, arresting the embryo development at the globular stage. This defined ABP1 as an essential protein required from early embryonic development with functions in cell division and elongation (Chen et al., 2001). However, embryo-lethal phenotype of abpl knock-out mutants has hampered its further functional characterization. This was rectified by the generation of transgenic lines conditionally downregulating ABP1 levels by ethanol-inducible immuno-modulation or antisense approaches that, despite entirely different technologies used, show the same phenotypes confirming the role of ABP1 in cell division and cell expansion (Braun et al., 2008; David et al., 2007).

Both downregulation lines along with the weak abpl-5 point mutation allele showed defects in clathrin-mediated endocytosis of PIN auxin export proteins (Dhonukshe et al., 2007; Petrášek et al., 2006) and their inhibition by auxin (Paciorek et al., 2005). In contrast, the ABP1 gain-of-function mutation has an opposite effect, promoting PIN internalization in tobacco cultured cells and stable Arabidopsis lines (Robert et al., 2010). Opposite effects of ABPl loss- and gain-of-function lines were observed also for auxin effects on arrangements of microtubules (Xu et al., 2014) and for controlling morphogenesis and shape of leaf epidermal pavement cells (Nagawa et al., 2012; Xu et al., 2010). Furthermore, the importance of auxin binding to ABP1 for gain-of-function phenotypes has been demonstrated by analysis of ABP1 variants with introduced mutations in the auxin binding pocket (Grones et al., 2015). Thus various types of loss- and gain-of-function strategies show an internally consistent picture of ABP1 signaling being involved in a range of physiological and cellular processes.

An important breakthrough came with the finding that the auxinbound ABP1 docks on the extracellular domain of the Transmembrane Kinase 1 (TMK1) (Dai et al., 2013; Xu et al., 2014) which added the missing piece to the puzzle of how the auxin signal is transmitted from the cell surface to the cytosol and further confirmed involvement of the ABP1/TMK1 pathway in auxinmediated development, particularly in pavement cell morphology (Grones \& Friml, 2015).

Surprisingly enough, shortly after these studies had been published, Gao et al. (2015) described two independent, full loss-of-function abpl mutants of A. thaliana (abpl-cl and abpl-TD1) that show no apparent developmental defects under normal growth conditions. This directly contradicts the embryo-lethal phenotypes of the originally described $a b p 1-1$ and $a b p 1-1 s$ lines (Chen et al., 2001; www. seedgenes.org/SeedGeneProfile?geneSymbol=ABP+1) and also questioned the relevance of the aforementioned studies.

The explanation of these contradictory results is therefore of crucial importance to understand the biological role of $\mathrm{ABP} 1$. In this study we aim to clarify the discrepancy between the dramatic embryolethal phenotype of the originally described $a b p 1$ knock-out mutants and the newly identified loss-of-function alleles.

\section{Material and methods}

Plant material and growth conditions

Arabidopsis thaliana mutants used in this study were: abpl-1 (Chen et al., 2001), abpl-1s (NASC accession N16148), abpl-cl, abp1-TD1 (Gao et al., 2015), bsm1-1 (Babiychuk et al., 1997). A. thaliana Col-0 wild type seeds were obtained from The Nottingham Arabidopsis Stock Centre (NASC, http://arabidopsis. info). The seeds were vernalized for 3 days in the dark at $4^{\circ} \mathrm{C}$. Plants were grown under long-day conditions (16-h light/8-h dark cycles) at $22^{\circ} \mathrm{C}$ in soil (Potgrond $\mathrm{P}$ ) : perlit $4: 1$ substrate and watered regularly with tap water.

For selection of $a b p 1-1, a b p 1-1 s$ and $b s m 1-1$ heterozygous plants, seeds were surface-sterilized with chlorine vapor and plated on 1/2 MS agar medium ( $\mathrm{pH} 5.9$ ) containing $1 \%(\mathrm{w} / \mathrm{v})$ sucrose and $25 \mu \mathrm{g} / \mathrm{mL}$ kanamycin according to Harrison et al. (2006).

\section{Coverage at the ABP1 locus}

Data from two publicly available short read libraries (NCBI Short Reads Archive accessions SRX759525 and SRX703650) from A. thaliana re-sequencing experiments were downloaded and mapped to the deposited reference genome TAIR10 (accessions NC_003070, NC_003071, NC_003074, NC_003075, NC_003076) using the Bowtie 2 plugin within the Geneious software, version 7.1.7 (http://www.geneious.com). For the first analyzed short read library (accession SRX759525), mapping parameters were set to a local alignment (“--very-fast-local”) with multi-mapping allowed 
(value $\mathrm{k}=10$ ). For the second analyzed short read library (accession SRX703650), mapping parameters were set to end-to-end alignment and the best-match mapping option $(\mathrm{k}=1)$ was used. In both cases the seed length (L) was set to 22 and number of mismatches $(\mathrm{N})$ to 1 . To maximize the mapping coverage short reads were mapped single-end. For all the remaining parameters the default Bowtie 2 values were used. For both alignments, the median coverage at the $A B P 1$ locus (bases 1319656 - 1321477 of NC_003075) was compared to the surrounding $20 \mathrm{Kbp}$ region (Figure 1A and 1B) and to the whole chromosome 4 (Figure 1C and Dataset 2 for SRX759525; Figure 1D and Dataset 3 for SRX703650). Mapping coverage is defined as the number of reads mapped to a given base. Coverage data from the Geneious software were exported and visualized using Matlab (v. R2011b).

A

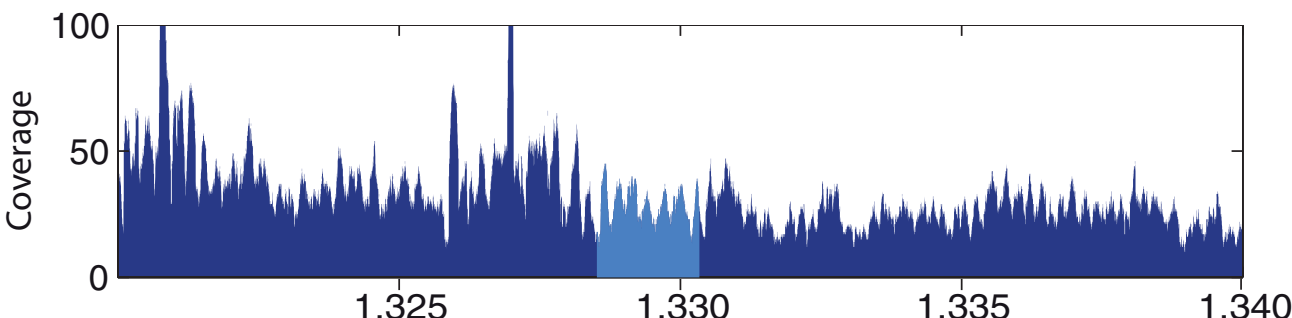

B

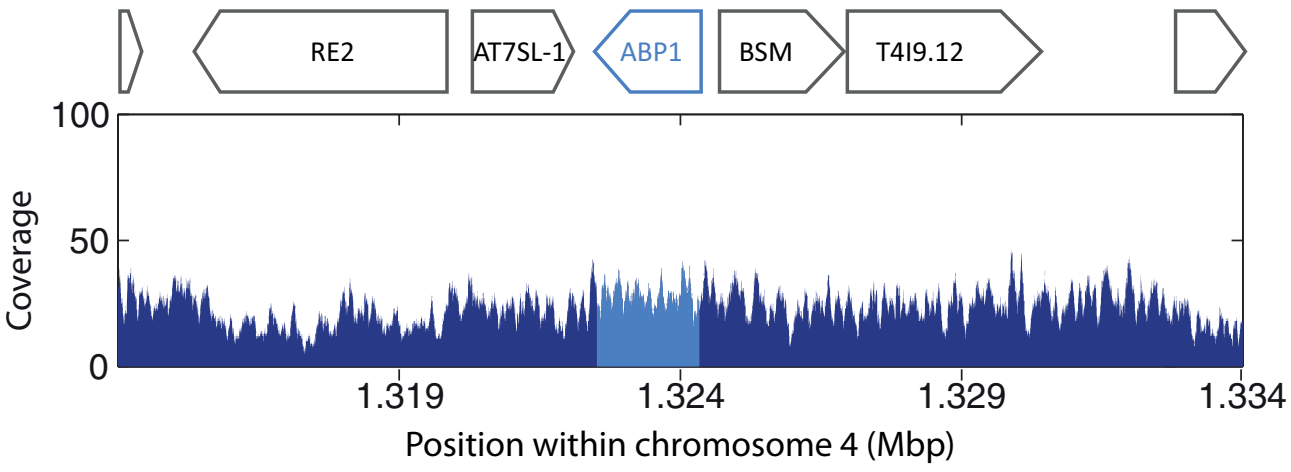

C

D

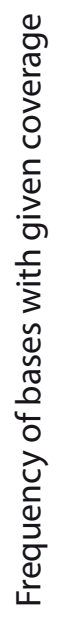

0.06
0.05
0.04
0.03
0.02
0.01
0


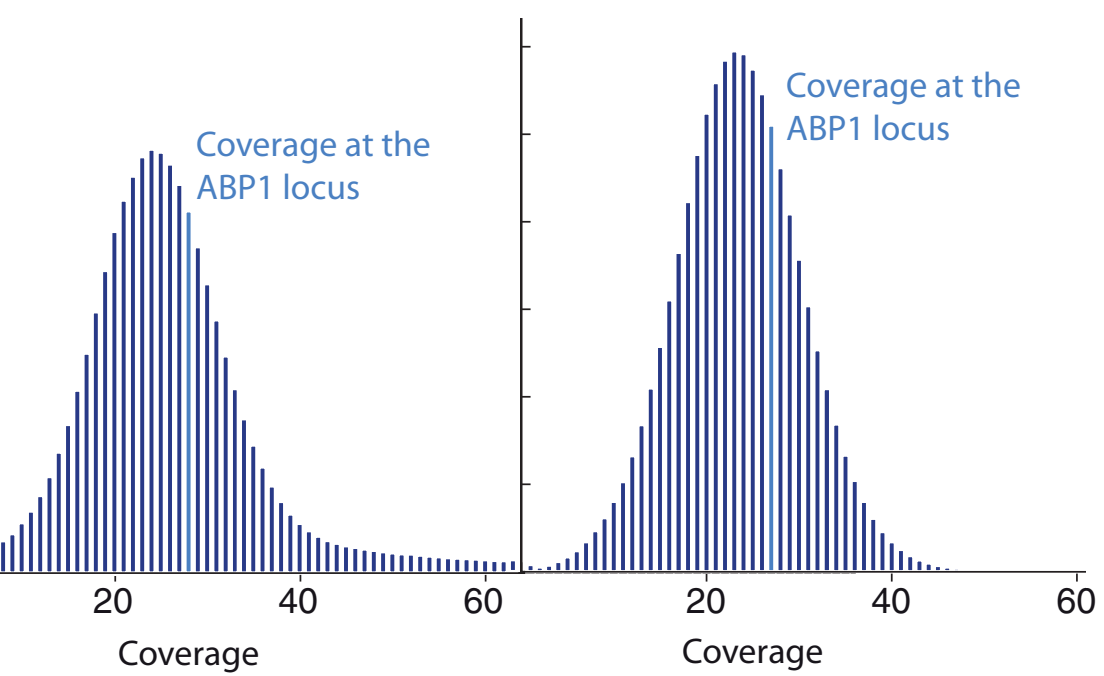

Figure 1. In silico mapping showed normal short read coverage at the $\boldsymbol{A B P} 1$ locus. To test the hypothesis of hidden $A B P 1$ duplicates in the genome of Arabidopsis thaliana, two short reads libraries from A. thaliana re-sequencing projects (NCBI accession numbers SRX759525 and SRX703650) were separately aligned to the reference Arabidopsis genome (TAIR10) using the BOWTIE 2 suit using different mapping parameter sets (see the Methods section). (A, B) The coverage of the $20 \mathrm{kbp}$ consensus sequence within the chromosome 4 that surrounds

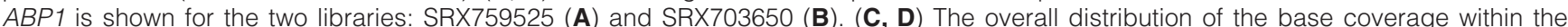
chromosome 4 is shown below. The median coverage at the ABP1 locus is highlighted in light blue and is well within the expected coverage values for both SRX759525 (C) and SRX703650 (D). 


\section{Genotyping mutants}

The T-DNA insertional mutants were genotyped by using a PCRbased method (Alonso et al., 2003). Amplification of PCR products was made using Phire Plant Direct PCR Kit (obtained from Thermo Scientific by Finnzymes, Espoo, Finland) following manufacturer's instructions for the dilution protocol and using Bio-Rad T100 Thermal Cycler. The PCR conditions were as follows: initial denaturation for $5 \mathrm{~min}$. at $98^{\circ} \mathrm{C}$ and subsequent 40 cycles: denaturation for $5 \mathrm{~s}$ at $98^{\circ} \mathrm{C}$, annealing for $10 \mathrm{~s}$ at the respective annealing temperature for each primer set (calculated with the Thermo Scientific Tm calculator; available at www.thermofisher.com), elongation for $30 \mathrm{~s}$ at $72^{\circ} \mathrm{C}$ and final elongation for $1 \mathrm{~min}$. at $72^{\circ} \mathrm{C}$.

Genotyping primers were as follows: cdsBSM_F and nptII_R for the bsm mutation, ABP1_3UTR_FOR and WiscDsLoc_REV for the abp1-1 mutation, WiscDsLoc_REV and qBSM_R2 for the abpl-1s mutation. Genotyping of abpl-cl and abpl-TD1 mutants was described previously (Gao et al., 2015). Sequences of all primers used in this study are listed in Table 1. Purified PCR products from plants positive for the presence of the T-DNA insertion were sequenced using a commercial service (LGC genomics, www.lgcgenomics.com). Primers used for sequencing were the same as for PCR. Sequence reads were aligned against $A$. thaliana genome (TAIR 10) using the BLAST tool (http://blast.ncbi.nlm.nih.gov/Blast.cgi). The position of the mutation was identified at the border of the sequence part aligned to $A B P 1$ locus and the sequence part aligned to the transformation vector. Position of individual mutations was mapped to the sequence of $A B P 1 / B S M$ locus acquired from the TAIR database (https://www.arabidopsis.org), visualized with the SnapGene Viewer software version 2.8.2 (http://www.snapgene.com/products/ snapgene_viewer) and edited in MS Power Point 2010.

\section{Quantitative RT-PCR}

For the RNA extraction approximately twenty 8 day-old seedlings were frozen in liquid nitrogen. Total RNA was extracted using the TRIzol reagent (Invitrogen, Carlsbad, CA, USA) and purified using RNeasy Mini Kit (Qiagen) according to manufacturer's instructions. For digestion of genomic DNA the following modification was incorporated into the protocol: in step 7, first $350 \mu \mathrm{L}$ of RW1 buffer was added to the RNeasy spin column and centrifuged (8000 rpm, room temperature, $15 \mathrm{~s}$ ). Subsequently, $40 \mu \mathrm{L}$ of the RNase-free recombinant DNase I incubation mix (mixture of $5 \mu \mathrm{L}$ DNase I and $35 \mu \mathrm{L}$ buffer RDD) (Roche) was added to the column and incubated for $15 \mathrm{~min}$ at room temperature. Next, another $350 \mu \mathrm{L}$ of RW1 buffer was added to the column and centrifuged again $(8000 \mathrm{rpm}$, room temperature, $15 \mathrm{~s}$ ). Two $\mu \mathrm{g}$ of purified DNase I pre-treated total RNA was used for a reverse transcription reaction using the iScript cDNA Synthesis Kit (BioRad, Hercules, CA, USA). Primers used for the quantitative RT-PCR were designed using QuantPrime (http://www.quantprime.de). For amplification of the BSM cDNA fragment ( 88 bp in length) primers qBSM_F2 and qBSM_R2 were used. The $A B P 1$ cDNA fragment (84 bp in length) was amplified with A2E and ABP1-586R primers. Arabidopsis tubulin beta chain 2 (TUB2, At5g62690) was used as a reference gene and amplified with TUB-2_F3 and TUB-2_R3 primer set (Table 1, Dataset 1). All primers were synthesized by commercial service (https://www. eurofinsgenomics.eu/). qRT-PCR was performed using the LightCycler 480 SYBR Green I Master chemistry (Roche) in a LightCycler 480 II thermal cycler (Ser. no. 5659, Roche) according to manufacturer's instructions. A 1:10 cDNA dilution was used as a template to prepare $5 \mu \mathrm{L}$ reaction mixture (final volume). The cycling conditions were as follows: pre-incubation for $10 \mathrm{~min}$. at $95^{\circ} \mathrm{C}$ and subsequent 45 cycles: denaturation for $10 \mathrm{~s}$ at $95^{\circ} \mathrm{C}$, annealing for

Table 1. Primers used in this study.

\begin{tabular}{|l|l|l|}
\hline Name & Sequence (5'-3') & Target \\
\hline Genotyping primers & & \\
\hline pSKTAIL-L3 & ATACGACGGATCGTAATTTGTCG & \\
\hline ABP1-U409F & CCTCATCACACAACAAAGTCACTC & \\
\hline ABP1-586R & GGAGCCAGCAACAGTCATGTG & \\
\hline cBSM_F & AAAAAACCTTACCCGCTCCTCTAA & \\
\hline nptII_R & AGCCAACGCTATGTCCTGAT & \\
\hline ABP13-UTR_FOR & GTATCTACGTAGTGTCACAAAACCTCAAC & \\
\hline WiscDsLOC_REV & TCCCAACAGTTGCGCACCTGAATG & \\
\hline qBSM_R2 & CCCAGGCTTTGTGAAGCCATTAC & BSM gene (At4g02990) \\
\hline Primers for qRT-PCR & & \\
\hline qBSM_F2 & TTTCCTCAGCTCCGGTAAAGAATG & ABP1 gene (At4g02980) \\
\hline qBSM_R2 & CCCAGGCTTTGTGAAGCCATTAC & TUB2 (At5g62690) \\
\hline A2E & TTGCCAATCGTGAGGAATATTAG & \\
\hline ABP1-586R & GGAGCCAGCAACAGTCATGTG & \\
\hline TUB-2_F3 & TAACAACTGGGCCAAGGGACAC & \\
\hline TUB-2_R3 & ACAAACCTGGAACCCTTGGAGAC & \\
\hline & & \\
\hline
\end{tabular}


$15 \mathrm{~s}$ at $60^{\circ} \mathrm{C}$, elongation for $15 \mathrm{~s}$ at $72^{\circ} \mathrm{C}$ followed by high resolution melting analysis. Gene expression was calculated with the 2- $\Delta \Delta \mathrm{CT}$ method (Livak \& Schmittgen, 2001). Individual experiments were made in a technical triplicate.

\section{Analysis of embryo defects}

To compare the stage of embryo arrest, seeds from siliques of the heterozygous abp $1-1$ and $b s m$ plants in the $7^{\text {th }}$ to $8^{\text {th }}$ developmental stage were used. For evaluation of embryo development, seeds from the siliques in the $3^{\text {rd }}$ to $5^{\text {th }}$ developmental stage were used. Siliques were dissected using a sharp needle and seeds were extracted and transferred onto microscopic slides into the drop of the Hoyer's solution (http://www.seedgenes.org/Tutorial.html) and cleared for $1 \mathrm{~h}$ similarly as described (Friml et al., 2003). The embryos were analyzed under $20 \times$ magnification using a digital camera system of the Olympus BX53 microscope by Normanski optics (Differential Interference Contrast (DIC) light microscopy). Images were processed in the ImageJ software, v. 1.48 (http://imagej.nih.gov/ij/) and mounted in Adobe Illustrator CS5.1.

\section{Allelic test}

Approximately 4 week-old plants were used for crossing. Flowers of recipient plants were emasculated 2 days before pollination. Crosses were generated by manual pollination. Green siliques were dissected 8 days after pollination and number of white and green seeds was counted and their ratio calculated.

\section{Results}

No hidden copy of the $A B P 1$ gene can be found in the genome of $A$. thaliana

One of the possibilities explaining at least some of the recent ABP1 controversies, in particular the strong phenotypes of the conditional lines versus no apparent phenotypes of the $a b p 1-c 1$ and $a b p 1-T D 1$ alleles, is the presence of a second, non-annotated $A B P 1$ gene copy in the genome of $A$. thaliana that is functionally redundant and not disrupted in the $a b p 1-c 1$ and $a b p 1-T D 1$ alleles. Highly similar copies of the $A B P 1$ gene are present in the annotated genomes of maize (Zea mays), rice (Oryza sativa) or poplar (Populus trichocarpa) (http://phytozome.jgi.doe.gov). During genome assembly, highly similar sequences such as transposons or recently duplicated genes could collapse into one copy resulting in no annotation of the duplicated copy (Stephane Rombauts, personal communication, $30^{\text {th }}$ January 2015). A non-annotated second copy of the $A B P 1$ gene is also present in the sequenced genome of the moss Physcomitrella patens (http://phytozome.jgi.doe.gov) raising the possibility that a similar situation could take a place in the A. thaliana genome.

We hypothesized that in case of a second non-annotated copy of $A B P 1$ in the A. thaliana genome, the short reads coverage at the $A B P 1$ locus would be doubled compared to the neighboring DNA regions and to the coverage of most other loci on the chromosome. To address this question we mapped short reads from two publicly available short read libraries from $A$. thaliana re-sequencing projects to the annotated Arabidopsis reference genome (TAIR 10) and analyzed the coverage at the $A B P 1$ locus.

As depicted (Figure 1), the number of aligned short reads at the $A B P 1$ locus is comparable with the short read coverage of the neighboring sequences and is well within the range of most common coverage values for loci on chromosome 4 indicating that no hidden copy of $A B P 1$ is present in the A. thaliana genome.

$A B P 1$ is tightly linked with a closely-located gene encoding for plastid-localized mTERF protein BSM important for embryogenesis

Another possibility to explain phenotypic discrepancies between different $a b p 1$ mutant alleles is a disruption of another gene in addition to $A B P 1$ that would be responsible for the strong phenotypes in the abp1-1 and abpl-1s alleles. As it can be seen on the $A B P 1$ locus map (Figure $2 \mathrm{~A}$ ), the $A B P 1$ gene is closely located to its neighboring gene $B S M$ in a head-to head orientation with translational start codons and 5'-UTR regions of the two genes being just $708 \mathrm{bp}$ and 381 bp respectively apart from each other. BSM encodes the mitochondrial transcription termination factor (mTERF)-like protein responsible for mitochondrial transcription termination in humans. In plants, mutants disrupting the BSM gene have been shown to be embryo-lethal (Babiychuk et al., 2011), therefore we suspected that the $B S M$ gene is the most likely off-target of mutations in the abpl-1 and abpl-1s alleles.

To look into this possibility closely, we mapped the relative position of individual mutations within the $A B P 1 / B S M$ locus (Figure 2A). Surprisingly, we found that the T-DNA insertion in $a b p 1-1 s$ mutant is in fact located in the $5^{\prime}$-UTR of the $B S M$ gene. Because $A B P 1$ and $B S M$ share a common promoter region, we hypothesized that the T-DNA insertion in abpl-1 could also disrupt the expression of the BSM gene thus causing the described embryonic lethality. Notably, the T-DNA insertion in the wild type-like allele abp 1-TD1 is located just $24 \mathrm{bp}$ apart from the abpl-1 T-DNA insertion and is even closer to the $B S M$ gene. We speculated that the dramatic phenotypic difference between both closely positioned T-DNAbased insertions might be caused by the presence of multiplied $35 \mathrm{~S}$ enhancers within the T-DNA construct in the abpl-TD1, because this allele was recovered from the activation tagging Arabidopsis mutant collection (SASKATOON) and harbors multiplied enhancers near the right T-DNA border on the inserted T-DNA element (Figure 2B).

To see whether the expression of the BSM gene in homozygous abpl-TD1 plants was affected by the T-DNA insertion, we performed a qRT-PCR analysis. Surprisingly, the BSM transcript levels in abp 1-TD1 were not substantially affected by the T-DNA insertion and were comparable to wild type Col-0 plants (Figure 2B). On the other hand, the expression of the $A B P 1$ gene was abolished in both $a b p 1-c 1$ and abpl-TD1 homozygous plants as reported previously (Gao et al., 2015). For abpl-1, abp1-1s or bsm mutants it was only possible to evaluate the $B S M$ expression in the heterozygous plants (due to the lethality of homozygous mutants) and this showed no substantial differences compared to wild type plants (Dataset 1).

Therefore, it is possible that while in the abpl-TD1 allele the expression of the $B S M$ gene is rescued by its ectopic expression driven by $35 \mathrm{~S}$ enhancers within the T-DNA, in the abpl-1 allele, where no such a mechanism exists, the expression of both genes may be disrupted. In addition, the $a b p 1-c 1$ null allele only contains a small $5 \mathrm{bp}$ deletion at the end of the first exon of $A B P 1$ which is 


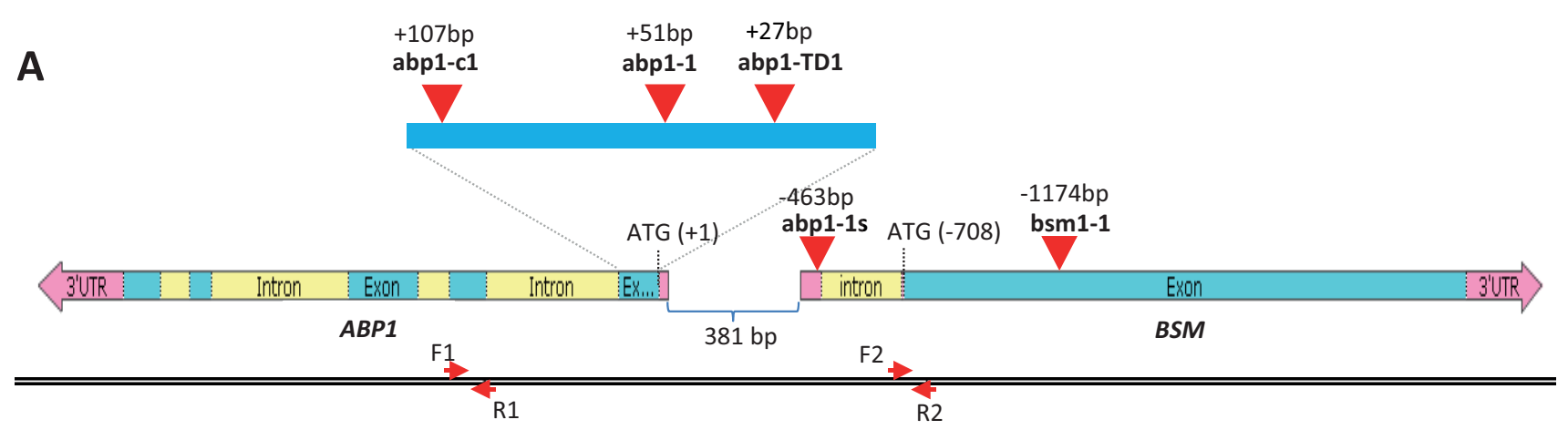

B
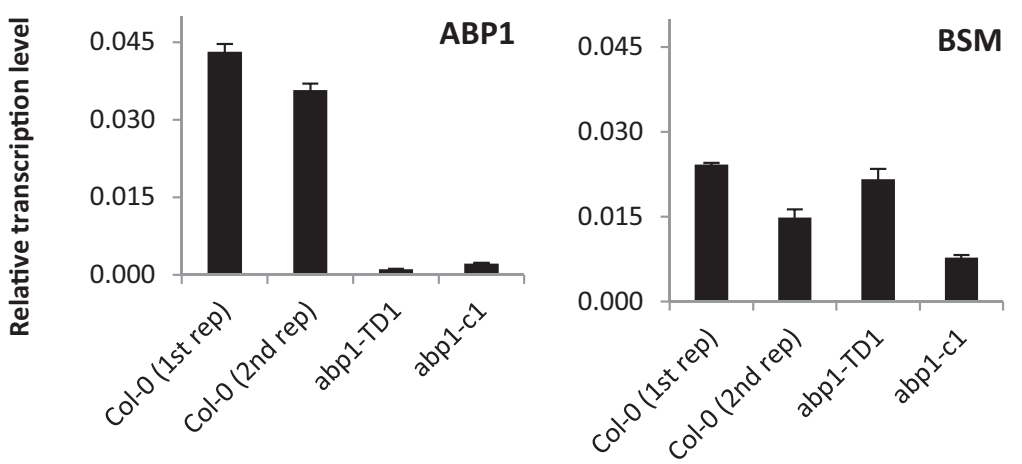

Figure 2. ABP1 is tightly linked with its neighboring gene BSM. (A) Map of the ABP1/BSM locus showing the mapped position of existing loss-of-function mutant alleles (red arrowheads) relative to the $A B P 1$ translation start. Note that the T-DNA insertion in abp 1-1s allele is located in the 5'-UTR region of the BSM gene. Positions of the forward primers ABP1-586R (F1) and qBSM_F2 (F2) and reverse primers A2E (R1) and qBSM_R2 (R2) used for the qRT-PCR are indicated by red arrows. (B) Quantitative real-time PCR of the ABP1 (left graph) and BSM (right graph) shows relative transcript levels in wild-type Col-0, abp1-c1 and abp1-TD1 seedlings. The reference gene was TUB2 (At5g62690). The transcript levels were calculated using $2-\Delta \Delta C T$ method. The data represent average relative quantity values of three technical replicates, and the bars denote standard errors. For wild-type Col-0 plants data from 2 biological replicates are shown.

less likely to have any effect on the $B S M$ gene compared to a few $\mathrm{kB}$ long T-DNA insertions in other alleles. Thus it is plausible that in abpl-1 and abpl-1s, both $A B P 1$ and BSM genes are disrupted.

abp1 and bsm knock-out mutants show similar defects in embryo development

To compare the embryo-lethal phenotypes of abpl-1 and abpl-1s alleles with the embryo-lethal phenotype of the bsml-1 T-DNA insertional knock-out allele, we analyzed the embryo development in siliques of $a b p 1-1, a b p 1-1 s$ and $b s m 1-1$ heterozygous plants along with homozygous new abpl knock-out alleles.

The inactivation of BSM gene by T-DNA insertion has been shown to cause an embryo arrest at the late globular stage of development (Babiychuk et al., 2011). In the abpl-1 mutants the embryo arrest has been reported at the early globular 32-cell stage in $25 \%$ of immature seeds (Chen et al., 2001). In both cases the homozygous mutant embryos never reach the heart-shape stage, indicating prevention in vertical elongation and subsequent anticlinal placement of division planes in the lower tier of cells. Other characteristic features reported in abpl-1 embryos have been connected with failure in degeneration of the suspensor structure and ectopic anticlinal divisions of basal cells resulting in longer suspensors at the later stages (Chen et al., 2001).

Inspection of embryos at different stages from the homozygous $a b p 1-c 1$ and $a b p 1-T D 1$ plants did not reveal any aberrations in the embryo development as compared to the wild type embryos (Figure 3) consistent with the lack of obvious postembryonic phenotypes (Gao et al., 2015). Also, no white aborted seeds were found in the older siliques of these plants (Supplementary Figure 1).

Opening and inspection of the older siliques in $a b p 1-1, a b p 1-1 s$ and bsm1-1 heterozygous plants did not reveal any visible differences between those alleles. In all three cases, the siliques carried approximately $25 \%$ of white aborted seeds (see Figure 4) containing developmentally arrested embryos (Figure 3). Analysis of the younger embryonic stages did not reveal any significant differences between 

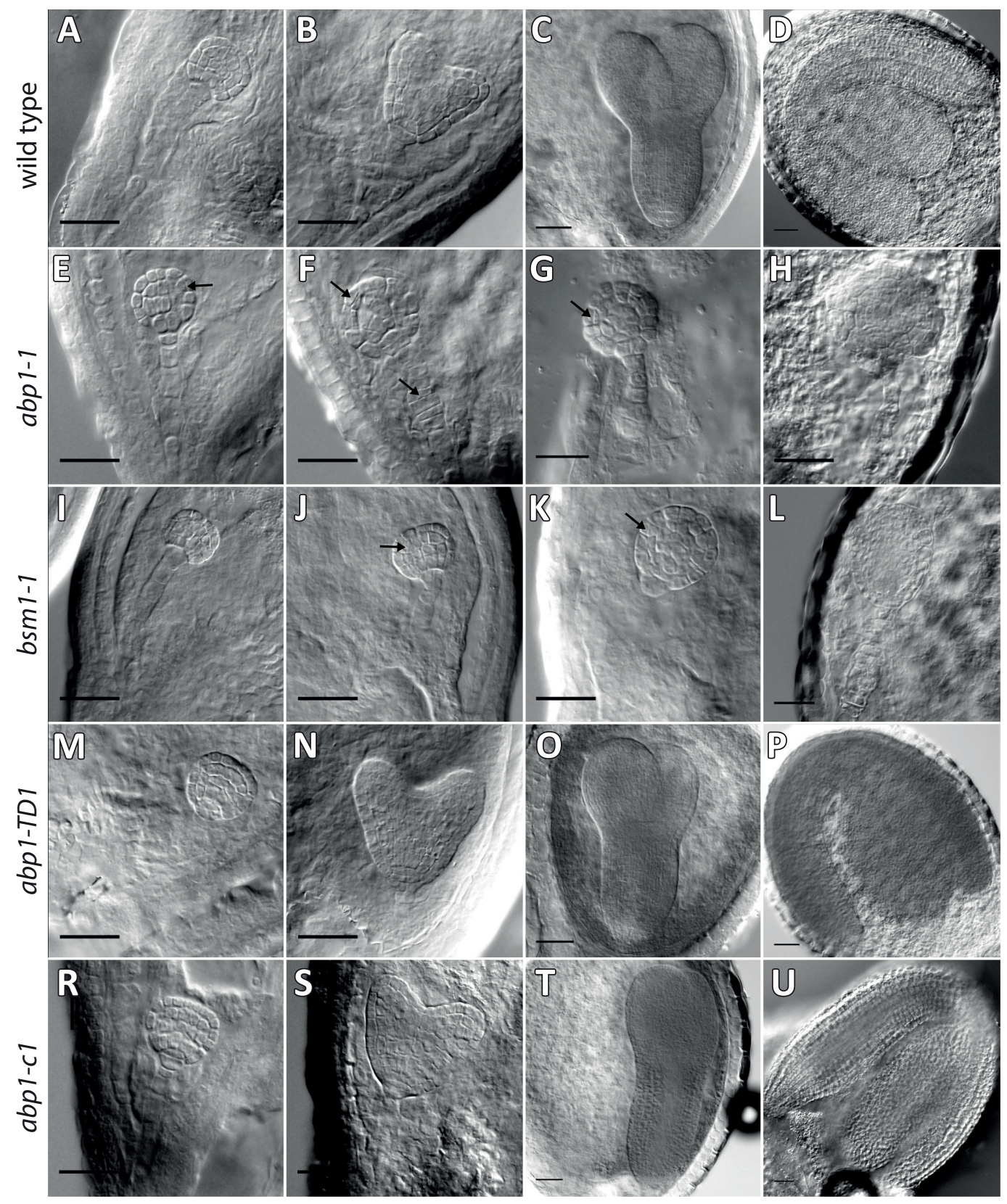

Figure 3. abp1-1 and bsm mutants show similar defects during embryo development. Seeds from the siliques of $a b p 1-1+/-(\mathbf{A}-\mathbf{H}), b s m+/-$ (I-L), abp1-TD1 -/- (M-P), and abp1-c1 -/- (R-U) plants at different developmental stages were isolated and cleared in Hoyer's solution and screened for defects in embryo development using Normanski optics. Wild type-looking embryos in the seeds of abp 1-1 mutant (A-D) showed normal developmental progression: the late globular stage $(\mathbf{A})$, early heart $(\mathbf{B})$, torpedo $(\mathbf{C})$ as well as the mature embryo stage $(\mathbf{D})$. At the globular stage we started to observe differences in embryo development between different mutants earliest manifested by periclinal divisions in protodermal cells (arrows) (A, E, I, M). When most of the wild-type embryos entered the early heart stage (B) some abp 1-1 embryos, from the same silique as (B) showed abnormal cell divisions (F), also visible in bsm (J) (arrows) but not in the abp1-TD1 (N) or abp1-c1 mutant (S). At the later stages of embryo development, when wild-type embryos in abp1-1 (C, D) as well as embryos in abp 1-TD1 (O, P) and abp 1-c1 (T, U) reached the torpedo $(\mathbf{C}, \mathbf{O}, \mathbf{T})$ and mature stage $(\mathbf{D}, \mathbf{P}, \mathbf{U})$, the mutant abp 1-1 $(\mathbf{G}, \mathbf{H})$ and bsm $(\mathbf{K}, \mathbf{L})$ embryos were still arrested at the late globular stage. While the bsm mutant embryos show signs of apical basal polarity, abp 1-1 embryos formed ball-shaped symmetric structure. Also, abnormal cell divisions in the suspensor cells were visible (arrows). Scale bars, $25 \mu \mathrm{m}$. 

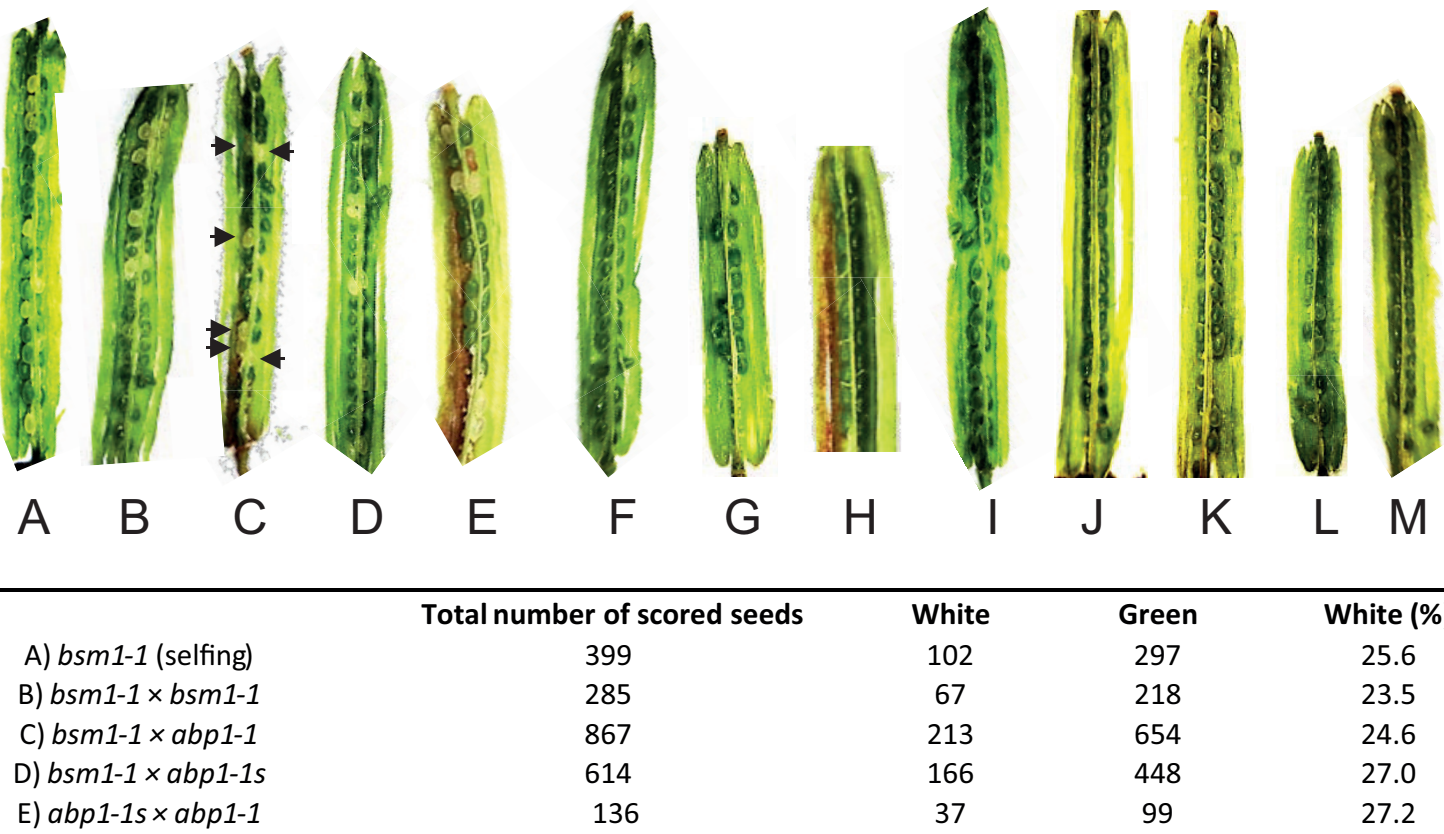

\title{
White
}

102

67

213

166

37

$\begin{array}{cc}\text { Green } & \text { White (\%) } \\ 297 & 25.6 \\ 218 & 23.5 \\ 654 & 24.6 \\ 448 & 27.0 \\ 99 & 27.2\end{array}$

\author{
F) $a b p 1-1 \times$ Col-0 \\ G) $a b p 1-1 s \times \mathrm{Col}-0$ \\ H) $b s m 1-1 \times \mathrm{Col}-0$
}

107

235

276

I) $b s m 1-1 \times a b p 1-c 1$

104

J) $a b p 1-T D 1 \times a b p 1-1 s$

195

K) $a b p 1-c 1 \times a b p 1-1 s$

284

L) $a b p 1-c 1 \times a b p 1-1$

M) $a b p 1-T D 1 \times a b p 1-1$

\begin{tabular}{lcl}
0 & 107 & 0.0 \\
0 & 235 & 0.0 \\
3 & 273 & 1.1 \\
0 & 104 & \\
1 & 194 & 0.0 \\
2 & 282 & 0.5 \\
1 & 106 & 0.7 \\
0 & 127 & 0.9 \\
\hline
\end{tabular}

Figure 4. Allelic test between $\boldsymbol{A}$. thaliana bsm and abp1 knock-out mutants. The embryolethal phenotype was detected in siliques 8 days after pollination by the presence of white seeds (arrested embryo development). It was not possible to complement the embryolethal phenotype of bsm mutant (A, B) with either abp1-1 or abp1-1s mutant (C, D). Similarly, abp 1-1 and abp1-1s mutants did not mutually complement $(\mathbf{E})$. As a control Col-0 plants were crossed into the abp1-1 (F), abp1-1s $(\mathbf{G})$ or bsm $(\mathbf{H})$ mutants showing complementation of the embryo-lethal phenotype. Genetic crosses of the recently identified abp1 null mutants (abp1-c1, abp1-TD1) with bsm (I), abp1-1s (J, K) or $\operatorname{abp1-1}(\mathbf{L}, \mathbf{M})$ lines resulted in complementation of the embryo-lethal phenotypes showing that in these lines the disruption of the BSM and not the $A B P 1$ gene is responsible for the embryo-lethal phenotype. Arrows indicate the position of white seeds in (C). Number of scored seeds for each cross and the percentage of white seeds are listed in the table below. Note that in not complementing crosses, the segregation of embryo-lethal seeds follows the Mendelian genetic laws as expected.

the analyzed alleles. The obvious embryo defects at the early globular stage were infrequent, and in both $a b p l$ and $b s m$ mutants started to be more pronounced at the late globular stage manifested by the failure of directional cell elongation leading to ball-shaped embryos at later stages. Another characteristic feature for both mutants was a disrupted cell division pattern with frequent periclinal divisions of outer layer cells (Figure 3B). At the later stages of embryo development, bsm mutant embryos showed some degree of apical-basal polarity by forming sometimes oval-shaped structures while abpl-1 mutant embryos continue to divide non-directionally forming more symmetrically ball-shaped embryos. These differences could be explained either by different backgrounds of the two mutant alleles (C24 in the case of bsm and Wassilewskija in the case of abpl-1, respectively) or by simultaneous disruption of both $A B P 1$ and $B S M$ genes in the abpl-1 mutant that may produce stronger effect as compared to a single BSM loss-of-function mutation in bsml-1. Despite these minor differences at the very late embryo stages, both mutations generated undistinguishable cell elongation and cell division pattern defects starting in both cases at the globular stage resulting in similar embryo-lethal phenotypes.

\section{Dysfunction of the BSM gene is responsible for embryonic} lethality of the abp1-1 and abp1-1s mutants

As the embryo-lethal phenotypes of $a b p l$ and $b s m$ mutants are indistinguishable from each other, we tested whether these phenotypes might be due to the mutations affecting the same gene or 
they are independently embryolethal. To address this hypothesis we performed allelic crosses between the bsm and $a b p 1-1$ as well as $a b p 1-1 s$ line and looked for the presence of white seeds carrying defective embryos within immature siliques 8 days after pollination of emasculated flowers. We assumed that if the mutations affect the same gene it will not be possible to complement the embryolethal phenotype of $a b p 1-1$ or $a b p 1-1 s$ mutants with a functional $A B P 1$ allele from the $b s m$ mutant which will result in the segregation of approximately $25 \%$ not developing (white) seeds in the F1 generation.

After dissection of siliques of $b s m 1-1 \times a b p 1-1, b s m 1-1 \times a b p 1-1 s$ or control crosses bsm1-1 $\times b s m 1-1$ and $a b p 1-1 s \times a b p 1-1$, we observed the presence of clearly distinguishable white seeds (Figure 4A-E). The segregation ratio of 1:4 white:green seeds was observed (Table in Figure 4, Supplementary Table 1) which is in perfect agreement with the Mendelian genetic laws implying that abpl-1 and abpl-1s mutants do not carry a functional BSM gene. On the other hand, when crossed with wild type (Col-0), abpl-cl or abpl-TD1 mutants, more than $99 \%$ of seeds in the siliques were green, indicating that a functional copy of the BSM gene present in these lines was able to complement the embryolethal phenotype of bsm1-1, abpl-1 and abpl-1s lines (Figure 4F-M).

In summary, these observations show that the described embryolethal phenotype of the $a b p 1-1$ and $a b p 1-1 s$ lines is caused by a disruption in the BSM gene.

\section{Dataset 1.}

http://dx.doi.org/10.5256/f1000research.7143.d104552

Quantitative RT-PCR data of the BSM and ABP1 gene expression level in different mutant lines (Michalko et al., 2015a).

\section{Dataset 2.}

http://dx.doi.org/10.5256/f1000research.7143.d104553

The short read coverage of individual bases at their respective positions within the Chromosome 4 of the Arabidopsis thaliana genome based on the mapping of short reads from Arabidopsis re-sequencing project (NCBI number: SRX759525) to the reference Arabidopsis genome (version TAIR10) (Michalko et al., 2015b).

\section{Dataset 3.}

http://dx.doi.org/10.5256/f1000research.7143.d104554

The short read coverage of individual bases at their respective positions within the Chromosome 4 of the Arabidopsis thaliana genome based on the mapping of short reads from Arabidopsis re-sequencing project (NCBI number: SRX703650) to the reference Arabidopsis genome (version TAIR10) (Michalko et al., 2015c).

\section{Discussion}

Embryo-lethal phenotypes of early abp1 knock-outs are caused by disruption of BSM

Since its discovery, the biological importance of the ABP1 protein as a plasma membrane auxin receptor has been a matter of debate, in part because of its predominant ER localization in plant cells where the conditions for auxin binding are unfavorable (Habets \& Offringa, 2015; Napier et al., 2002). Nonetheless, after the two independently isolated Arabidopsis abpl loss-of-function alleles were reported to be embryolethal (Chen et al., 2001; www.seedgenes.org/SeedGeneProfile?geneSymbol=ABP+1), the crucial importance of this protein in cell division and elongation was accepted. This view was challenged by the isolation of two new knock-out alleles (Gao et al., 2015) that harbor mutations in a close vicinity to the previously published insertions and show no obvious phenotypes.

The phenotype of the originally reported abpl-1 mutant was reported to be complemented by the $35 S:: A B P 1$ overexpression construct (Chen et al., 2001). However, despite multiple attempts it was not possible to repeat this complementation either with constructs for overexpression of the wild type $A B P 1$ copy or by the genomic fragment (Grones et al., 2015). Altogether, these findings implied that there exists another cause for the drastic phenotypes present in the abpl-1 and abpl-1s mutants.

Here we show that the neighboring gene $B S M$, which has been shown previously to be crucial for embryogenesis in Arabidopsis (Babiychuk et al., 2011) is likely to be also disrupted by the T-DNA insertions in the original $a b p 1-1$ and abpl-1s mutants, but not in the newly isolated loss-of-function lines $a b p 1-c 1$ and $a b p 1-T D 1$. Furthermore, we demonstrate that the mutant embryos of abpl-1 and $a b p 1-1 s$ as well as the loss-of-function $b s m 1-1$ allele showed similar embryo phenotypes and are arrested at the globular stage as it was shown in the original studies (Babiychuk et al., 2011; Chen et al., 2001).

By allelic complementation experiments we showed that the embryolethal phenotype of the original $a b p 1-1$ and $a b p 1-1 s$ alleles can be complemented by the functional copy of the BSM gene that is present in the new $a b p 1-c 1$ and $a b p 1-T D 1$ alleles, but not by the bsm loss-of-function or the abpl-1 mutants themselves. Therefore, the originally described $a b p l$ mutants are, indeed, loss-of-function alleles of the $B S M$ gene and at least abpl-1 is a double loss-offunction mutant of $A B P 1$ and $B S M$. Thus, the embryo-lethal phenotype previously attributed to the $a b p l$ loss-of-function alleles is a result of the mutation in the neighboring BSM gene. For this reason, we also propose to re-annotate the $a b p 1-1$ and $a b p 1-1 s$ alleles as $a b p 1-1 / b s m 1-2$ and $b s m 1-3$ (for this line it remains unclear if the insertion disrupts both $A B P 1$ and $B S M$ expression), respectively.

Functional importance of the ABP1 pathway

The $a b p l$ and $b s m$ allelic test together with no embryonic defects in the true abpl knock-out lines makes it clear that no role has 
been identified for ABP1 in early embryogenesis. However, this clarification of abpl knock-out genotypes does not per se undermine all experimentation with $A B P 1$ genetic tools. The other $A B P 1$ genotypes comprise conditional and constitutive gain-of-function alleles, two types of conditional knock-downs, as well as a weak abp1-5 point mutation (Braun et al., 2008; Covanova et al., 2013; Grones et al., 2015; Robert et al., 2010; Tromas et al., 2009; Xu et al., 2010). In several analyzed cellular processes including auxindependent ROP-GTPase activation, auxin-regulated endocytosis, E3 ligase-mediated ubiquitination, or cortical microtubule reorientation (Robert et al., 2010; Sassi et al., 2014; Tromas et al., 2013; $\mathrm{Xu}$ et al., 2010; Xu et al., 2014) this genetic material produced fully internally consistent data sets. Furthermore, loss-of-function mutants in TMK receptor-like protein kinases, which interact with ABP1 in an auxin-inducible manner, show largely overlapping phenotypes with abpl mutants (Xu et al., 2014). Altogether, these data support the importance of the ABP1/TMK auxin perception and signaling mechanism in plant development and physiology. One possible explanation for the absence of obvious phenotype defects in true abpl knock-outs is a presence of another copy of the $A B P 1$ gene in the genome of $A$. thaliana that could escape the gene annotation during genome assembly and that could stay undetected by Southern blot analysis if the two copies were located close together. However, by in silico analysis of the ABP1 locus coverage we excluded this possibility. Other possible ways to reconcile the absent phenotype defects in the knock-outs with observations from the other genetic material include a genetic compensation mechanism that can be triggered by independent deleterious lossof-function mutations but not by the genetic knock-downs of the same genes as shown for example in zebrafish (Rossi et al., 2015). Such compensation machinery could involve previously largely overlooked ABP1-like proteins from the germin family that are not a close sequence homologs of ABP1 but share some common characteristic features and some of them have been identified by their binding to auxin (reviewed in Napier et al., 2002).

Importantly, with the controversy of the embryonic phenotypes in different $a b p 1$ mutant alleles clarified, we can move on and with the updated genetic toolbox clarify the role of ABP1 in auxin signaling and plant development. The high affinity binding of ABP1 to auxin, universal occurrence of the $A B P 1$ genes in the genomes from algae to higher plants and its highly conserved structure argue for its importance throughout the plant kingdom and promise further interesting discoveries.

\section{Data availability \\ F1000Research: Dataset 1. Dataset 1, 10.5256/f1000research.7143. d104552}

F1000Research: Dataset 2. Dataset 2, 10.5256/f1000research.7143. d104553

F1000Research: Dataset 3. Dataset 3, 10.5256/f1000research.7143. d104554

\section{Author contributions}

JF and JM designed the experiments and wrote the manuscript, JM performed all experiments and analyzed the data except the short read coverage experiment, MD performed the genome coverage experiment, analyzed the data and helped with writing the manuscript, TB helped with planning and evaluating the genome coverage experiment. All authors have seen and agreed to the final content of the manuscript.

\section{Competing interests}

No competing interests were disclosed.

\section{Grant information}

This work was supported by ERC Independent Research grant (ERC-2011-StG-20101109-PSDP to JF). JM internship was supported by the grant "Action Austria - Slovakia".

\section{Acknowledgements}

We would like to thank Elena Babiychuk and Sergei Kushnir for providing bsm1-1 mutant seeds. We also like to thank Stephane Rombauts for useful advices for genome coverage analysis. We are thankful to Daniel von Wangenheim for final processing of the images.

\section{Supplementary materials}

\section{Supplementary Table 1}

Allelic test between A. thaliana bsm and abpl knock-out mutants. Complete table with number of scored seeds for all crosses made. The percentage of white seeds from the total number of scored seeds is shown in brackets for each tested combination. N/A = data not available, 우 $=$ plant was used as a pollen recipient, $\sigma^{\top}=$ plant was used as a pollen donor.

Click here to access the data.

\section{Supplementary Figure 1}

Dissected immature siliques of $a b p 1-T D 1$ and $a b p 1-c 1$ mutants.

Click here to access the data. 
Alonso JM, Stepanova AN, Leisse TJ, et al:: Genome-wide insertional mutagenesis of Arabidopsis thaliana. Science. 2003; 301(5633): 653-657. PubMed Abstract | Publisher Full Text

Babiychuk E, Fuangthong M, Van Montagu M, et al.: Efficient gene tagging in Arabidopsis thaliana using a gene trap approach. Proc Natl Acad Sci U S A. 1997; 94(23): 12722-12727.

PubMed Abstract | Free Full Text

Babiychuk E, Vandepoele K, Wissing J, et al:: Plastid gene expression and plant development require a plastidic protein of the mitochondrial transcription termination factor family. Proc Natl Acad Sci U S A. 2011; 108(16): 6674-6679. PubMed Abstract | Publisher Full Text | Free Full Text

Batt S, Wilkins MB, Venis MA: Auxin binding to corn coleoptile membranes: Kinetics and specificity. Planta. 1976; 130(1): 7-13.

PubMed Abstract | Publisher Full Text

Braun N, Wyrzykowska J, Muller P, et al:: Conditional repression of AUXIN BINDING PROTEIN1 reveals that it coordinates cell division and cell expansion during postembryonic shoot development in Arabidopsis and tobacco. Plant Cell. 2008; 20(10): 2746-2762.

PubMed Abstract | Publisher Full Text | Free Full Text

Chen JG, Ullah H, Young JC, et al.: ABP1 is required for organized cell elongation and division in Arabidopsis embryogenesis. Genes Dev. 2001; 15(7): 902-911.

PubMed Abstract | Publisher Full Text | Free Full Text

Cosgrove DJ: Loosening of plant cell walls by expansins. Nature. 2000; 407(6802): 321-326

PubMed Abstract | Publisher Full Text

Čovanová M, Sauer M, Rychtáŕ J, et al.: Overexpression of the auxin binding protein1 modulates PIN-dependent auxin transport in tobacco cells. PLOS One. 2013; 8(7): e70050

PubMed Abstract | Publisher Full Text | Free Full Text

Dai N, Wang W, Patterson SE, et al:: The TMK subfamily of receptor-like kinase in Arabidopsis display an essential role in growth and a reduced sensitivity to auxin. PLoS One. 2013; 8(4): e60990.

PubMed Abstract | Publisher Full Text | Free Full Text

David KM, Couch D, Braun N, et al: The auxin-binding protein 1 is essential for the control of cell cycle. Plant J. 2007; 50(2): 197-206.

PubMed Abstract | Publisher Full Text

Dhonukshe $\mathrm{P}$, Aniento F, Hwang I, et al.: Clathrin-mediated constitutive endocytosis of PIN auxin efflux carriers in Arabidopsis. Curr Biol. 2007; 17(6): $520-527$.

PubMed Abstract | Publisher Full Text

Enders TA, Strader LC: Auxin activity: Past, present, and future. Am J Bot. 2015; 102(2): 180-196.

PubMed Abstract | Publisher Full Tex

Friml J, Benková E, Mayer U, et al.: Automated whole mount localisation techniques for plant seedlings. Plant J. 2003; 34(1): 115-124.

PubMed Abstract | Publisher Full Tex

Gao $Y$, Zhang $Y$, Zhang $D$, et al:: Auxin binding protein 1 (ABP1) is not required for either auxin signaling or Arabidopsis development. Proc Natl Acad Sci U S A. 2015; 112(7): 2275-2280.

PubMed Abstract | Publisher Full Text | Free Full Text

Grones $\mathrm{P}$, Chen X, Simon S, et al.: Auxin-binding pocket of ABP1 is crucial for its gain-of-function cellular and developmental roles. J Exp Bot. 2015; 66(16): 5055-65.

PubMed Abstract | Publisher Full Tex

Grones $\mathrm{P}$, Friml J: Auxin transporters and binding proteins at a glance.

J Cell Sci. 2015; 128(1): 1-7.

PubMed Abstract | Publisher Full Text

Grunewald W, Friml J: The march of the PINs: developmental plasticity by dynamic polar targeting in plant cells. EMBO J. 2010; 29(16): 2700-2714. PubMed Abstract | Publisher Full Text | Free Full Text

Habets ME, Offringa R: Auxin Binding Protein 1: A Red Herring After All? Mol Plant 2015; 8(8): 1131-4.

PubMed Abstract | Publisher Full Text

Harrison SJ, Mott EK, Parsley K, et al.: A rapid and robust method of identifying transformed Arabidopsis thaliana seedlings following floral dip transformation. Plant Methods. 2006; 2(1): 19

PubMed Abstract | Publisher Full Text | Free Full Text

Hertel R, Thomson KS, Russo VE: In-vitro auxin binding to particulate cell

fractions from corn coleoptiles. Planta. 1972; 107(4): 325-340.

PubMed Abstract | Publisher Full Text

Löbler M, Klämbt D: Auxin-binding protein from coleoptile membranes of corn
(Zea mays L.). I. Purification by immunological methods and characterization. J Biol Chem. 1985; 260(17): 9848-9853.

PubMed Abstract

Livak KJ, Schmittgen TD: Analysis of relative gene expression data using realtime quantitative PCR and the 2(-Delta Delta C(T)) Method. Methods. 2001; 25(4): 402-408

PubMed Abstract | Publisher Full Text

Michalko J, Dravecka M, Bollenbach T, et al.: Dataset 1 in: Embryo-letha phenotypes in early abp1 mutants are due to disruption of the neighboring BSM gene. F1000Research. 2015a.

Data Source

Michalko J, Dravecka M, Bollenbach T, et al: Dataset 2 in: Embryo-lethal phenotypes in early abp1 mutants are due to disruption of the neighboring BSM gene. F1000Research. 2015b.

Data Source

Michalko J, Dravecka M, Bollenbach T, et al.: Dataset 3 in: Embryo-lethal phenotypes in early abp1 mutants are due to disruption of the neighboring BSM gene. F1000Research. 2015c.

Data Source

Nagawa S, Xu T, Lin D, et al:: ROP GTPase-dependent actin microfilaments promote PIN1 polarization by localized inhibition of clathrin-dependent endocytosis. PLoS Biol. 2012; 10(4): e1001299.

PubMed Abstract | Publisher Full Text | Free Full Text

Napier RM, David KM, Perrot-Rechenmann C: A short history of auxin-binding proteins. Plant Mol Biol. 2002; 49(3-4): 339-348, Springer Netherlands.

PubMed Abstract | Publisher Full Text

Paciorek T, Zažímalová E, Ruthardt N, et al.: Auxin inhibits endocytosis and promotes its own efflux from cells. Nature. 2005; 435(7046): 1251-1256. PubMed Abstract | Publisher Full Text

Petrášek J, Mravec $\mathrm{J}$, Bouchard $\mathrm{R}$, et al: PIN proteins perform a rate-limiting function in cellular auxin efflux. Science. 2006; 312(5775): 914-918.

PubMed Abstract | Publisher Full Text

Ray PM, Dohrmann U, Hertel R: Characterization of naphthaleneacetic Acid binding to receptor sites on cellular membranes of maize coleoptile tissue. Plant Physiol. 1977: 59(3): 357-364.

PubMed Abstract | Publisher Full Text | Free Full Text

Robert S, Kleine-Vehn J, Barbez E, et al.: ABP1 mediates auxin inhibition of clathrin-dependent endocytosis in Arabidopsis. Cell. 2010; 143(1): 111-121. PubMed Abstract | Publisher Full Text | Free Full Text

Rossi A, Kontarakis Z, Gerri C, et al.: Genetic compensation induced by deleterious mutations but not gene knockdowns. Nature. 2015; 524(7564): 230-233.

PubMed Abstract | Publisher Full Text

Sassi M, Ali O, Boudon F, et al:: An auxin-mediated shift toward growth isotropy promotes organ formation at the shoot meristem in Arabidopsis. Curr Biol. 2014; 24(19): 2335-2342.

PubMed Abstract | Publisher Full Text

Steffens $\mathrm{B}$, Feckler $\mathrm{C}$, Palme $\mathrm{K}$, et al: The auxin signal for protoplast swelling is perceived by extracellular ABP1. Plant J. 2001; 27(6): 591-599.

PubMed Abstract | Publisher Full Text

Tromas A, Braun N, Muller $\mathrm{P}$, et al.: The AUXIN BINDING PROTEIN 1 is required for differential auxin responses mediating root growth. PLoS One. 2009; 4(9): e6648.

PubMed Abstract | Publisher Full Text | Free Full Text

Tromas A, Paque S, Stierlé V, et al:: Auxin-binding protein 1 is a negative regulator of the SCF TIR/AFB pathway. Nat Commun. 2013; 4: 2496.

PubMed Abstract | Publisher Full Text

Tzafrir I, Pena-Muralla R, Dickerman A, et al.: Identification of genes required for embryo development in Arabidopsis. Plant Physiol. 2004; 135(3): 1206-1220. PubMed Abstract | Publisher Full Text | Free Full Text

Woo EJ, Marshall J, Bauly $\mathrm{J}$, et al: Crystal structure of auxin-binding protein 1 in complex with auxin. EMBO J. 2002; 21(12): 2877-2885.

PubMed Abstract | Publisher Full Text | Free Full Text

Xu T, Wen M, Nagawa S, et al:: Cell surface- and rho GTPase-based auxin signaling controls cellular interdigitation in Arabidopsis. Cell. 2010; 143(1): 99-110.

PubMed Abstract | Publisher Full Text | Free Full Text

Xu T, Dai N, Chen J, et al.: Cell surface ABP1-TMK auxin-sensing complex activates ROP GTPase signaling. Science. 2014; 343(6174): 1025-1028. PubMed Abstract | Publisher Full Text | Free Full Text

Yamagami M, Haga K, Napier RM, et al:: Two distinct signaling pathways participate in auxin-induced swelling of pea epidermal protoplasts. Plant Physiol. 2004; 134(2): 735-747.

PubMed Abstract | Publisher Full Text | Free Full Text 


\section{Open Peer Review}

\section{Current Peer Review Status:}

\section{Version 1}

Reviewer Report 02 November 2015

https://doi.org/10.5256/f1000research.7695.r10913

(C) 2015 Luschnig C. This is an open access peer review report distributed under the terms of the Creative Commons Attribution License, which permits unrestricted use, distribution, and reproduction in any medium, provided the original work is properly cited.

\section{Christian Luschnig}

Department of Applied Genetics and Cell Biology, University of Natural Resources and Life Sciences, Vienna, Austria

After publication of an article by Gao and colleagues earlier this year, several published results dealing with the role of $A B P 1$ in auxin signaling and plant development became a matter of doubt. This also concerns the embryo-lethal phenotypes that have been attributed to a loss of $A B P 1$ function in $a b p 1-1$ and $a b p 1-1 s$ alleles - quite the opposite of the wild type appearance of the likely $a b p 1-1 c$ and abp1-TD1 null alleles, described by Gao and colleagues. These contradicting results predict off-target effects that would cause phenotypes associated with abp1-1 and abp1-1s, and the authors of this study attempted to identify such targets.

From the results presented in this manuscript it appears that functional disruption of the $B S M$ gene, located proximal to $A B P 1$, is responsible for abp1-1/abp1-1s embryo-lethal phenotypes. This is indicated by genetic complementation analyses, demonstrating that neither abp1-1 nor abp1-1s complement segregation of bsm1-1 embryo-lethal phenotypes, when analyzing progeny of crosses. On the other hand, when introducing bsm1-1 into abp1-c1 and abp1-TD1, the authors observed complementation of embryo-lethal phenotypes. This provides genetic evidence for a scenario in which phenotypes associated with abp1-1 and abp1-1s result from disruption of the BSM1 locus.

This is an important and timely report, summarizing experiments that certainly will contribute to our understanding of $A B P 1$ function in Arabidopsis. Specifically, it finally establishes an off-target candidate locus, responsible for abp1 mutant phenotypes that have been an integral part of a number of published studies.

With respect to the title:

"early abp1 mutants" sounds a bit ambiguous. The authors might consider "original abp1 mutants" instead

Competing Interests: No competing interests were disclosed. 


\section{I confirm that I have read this submission and believe that I have an appropriate level of expertise to confirm that it is of an acceptable scientific standard.}

Reviewer Report 02 November 2015

https://doi.org/10.5256/f1000research.7695.r10914

(C) 2015 Napier R. This is an open access peer review report distributed under the terms of the Creative Commons Attribution License, which permits unrestricted use, distribution, and reproduction in any medium, provided the original work is properly cited.

\section{Richard M. Napier}

School of Life Sciences, University of Warwick, Coventry, UK

This manuscript examines the genotypic basis behind distinctly different phenotypes which have been reported for arabidopsis mutant lines each annotated as abp1 knock-out/loss-of-function alleles. The various mutant lines as homozygotes have been reported over time both as conferring embryo lethality and as displaying no obvious phenotype. Naturally, each outcome translates into very different interpretations of the function and relevance of ABP1. Consequently, clarification of the genotypes behind each phenotype is welcome. This paper maps the mutation sites in each allele and ties embryo lethality to disruption of the adjacent gene BSM. Thus, ABP1 is not necessary for embryo development in arabidopsis. I applaud the clarity of the conclusion and the suggestion to rename the misleading lines.

The title is appropriate and factual. The abstract is appropriate. The experimental strategy is direct and sound, methods are described well and suitable statistical analyses have been employed. All the data are presented clearly and are accessible. The text is clear and well structured.

Following the conclusion drawn from the data presented here, there is a discussion on how this and the report of Gao et al affect our understanding of the biological role of ABP1 in planta. It is clear that in the case of ABP1 molecular genetic techniques have provided misleading genotypes. Thank goodness this is now cleared up. The case made in the discussion is that these specific false leads do not undermine all ABP1 results where the results are based on different genotypes and complementary tools. This is in stark contrast to the case suggested by the somewhat provocative title of the Gao paper. The phenotypes considered differ in timing and detail, but this paper and that of Gao et al are linked by revelations clarifying $A B P 1$ mutant genotypes. The contrasting perspective offered by the discussion contributes to a healthy, objective dialogue.

Minor points:

Throughout I believe 'Normanski' should read Nomarski optics.

In the results section, text associated with the $35 \mathrm{~S}$ inserts from SASKATOON accessions should refer to Fig $2 \mathrm{~A}$ (not 2B).

Technical replicates are used for the QPCR data, and where biological replicates are shown there is clearly more variation than between technical replicates, but interpretations of the result are not affected by this level of uncertainty. However, I am not sure the use of "Surprisingly" is necessary 
in the text (page 5, right column) considering the qPCR data for BSM transcripts in Fig 2B. "In contrast to the loss of ABP1 transcript..." might be more appropriate at this stage of the narrative. Perhaps reordering consideration of the two sets of data (especially given the ABP1 data are shown first in the figure) would help here.

Competing Interests: No competing interests were disclosed.

I confirm that I have read this submission and believe that I have an appropriate level of expertise to confirm that it is of an acceptable scientific standard.

Reviewer Report 02 November 2015

https://doi.org/10.5256/f1000research.7695.r10911

(C) 2015 Ostergaard L. This is an open access peer review report distributed under the terms of the Creative Commons Attribution License, which permits unrestricted use, distribution, and reproduction in any medium, provided the original work is properly cited.

\section{Lars Ostergaard}

Department of Crop Genetics, John Innes Centre, Norwich, UK

This article provides a clear introduction to the current controversy regarding the Auxin Binding Protein1 (ABP1). The authors have carried out a thorough genetic analysis which shows that the embryo lethality of the abp1-1 and abp1-1s mutants previously assigned to the loss of ABP1 function is in fact due to loss of the neighbouring gene, BELAYA SMERT (BSM).

Competing Interests: No competing interests were disclosed.

I confirm that I have read this submission and believe that I have an appropriate level of expertise to confirm that it is of an acceptable scientific standard. 
The benefits of publishing with F1000Research:

- Your article is published within days, with no editorial bias

- You can publish traditional articles, null/negative results, case reports, data notes and more

- The peer review process is transparent and collaborative

- Your article is indexed in PubMed after passing peer review

- Dedicated customer support at every stage

For pre-submission enquiries, contact research@f1000.com 